\title{
O JOGO DE CENA, O GRUPO, O PALCO: SOBRE RISCOO \\ JOGO DE CENA, O GRUPO, O PALCO: SOBRE RISCOS E/OU \\ TÁBUA(S) DE SALVAÇÃO? UM DISPOSITIVO DE MEDIAÇÃO TEATRAL PARA ADOLESCENTES E JOVENS \\ ADULTOS $^{3839}$ \\ Entrevista com Nathalie Sevilla
}

Dominique Mahyeux ${ }^{40}$

"Impõe tua sorte, abraça tua alegria e vai ao encontro do risco. Ao te olharem, acabarão te aceitando."

René Char, Les Matinaux, 1950.

Dominique Mahyeux: A senhora é diretora teatral e diretora artística da companhia na qual desenvolveu O Laboratório de Teatro, um dispositivo de mediação cultural, que tem como foco um público adolescente em dificuldade. O nome teria sido uma homenagem ao Teatro Laboratório, de Jerzy Grotowski? E, além disso, a senhora poderia nos apresentar um pouco dessa iniciativa, nos dizer o que induziu sua escolha e, em termos mais gerais, qual foi sua trajetória?

Nathalie Sevilla: Sou professora de educação artística, da subdivisão de Teatro, em um conservatório da região parisiense e, também, responsável por formações no âmbito da mediação teatral, junto a profissionais que trabalham em instituições psiquiátricas. Essa questão da transmissão é fundamental para mim e sempre foi o âmago do meu trabalho. Além disso, sou diretora teatral e artística da Companhia À Force de Rêver ${ }^{41}$. Em 2000, tivemos a ideia de criar, na companhia, um dispositivo dedicado exclusivamente a um público juvenil (adolescentes e jovens adultos). Em seguida, escolhemos o nome Laboratório de Teatro, como se estivéssemos dando um sinal para Jerzy Grotowski ${ }^{42}$. Quando jovem comediante, eu tive a oportunidade de participar de um

\footnotetext{
${ }^{38}$ Artigo original disponível em https://www.cairn.info/revue-de-l-enfance-et-de-l-adolescence-2018-1page-127.htm

39 Traduzido por Luckas Catojo, Mônica Fiuza BF, Rafael Rodrigues e Thainá Carungaba, no LABESTRAD/UFF, Junho de 2019; Revisão da tradução: Marília Etienne Arreguy, psicanalista, Professora Associada I - UFF.

40 Psicanalista da Protection Judiciaire de la Jeunesse. E-mail : dom.mahyeux@wanadoo.fr

${ }^{41}$ N.T.: De tanto sonhar. O nome da companhia expressa a resistência presente no ato de sonhar.

42 N.A.: Jerzy Grotowski (1933-1999) é um diretor teatral polonês, teórico de teatro e pedagogo. É um dos maiores reformadores do teatro do século XX. Em 1962, instala seu Teatro Laboratório (TeatrLaboratorium) na Breslávia, uma cidade da Baixa Silésia. Ele trabalhou no Colégio de França, de 1997 a 1999.
} 


\section{RevistAleph}

estágio, muitíssimo importante para mim, com o ator Richard Sciezlack, um dos "queridinhos" de Grotowiski, que me apresentou o trabalho deste.

Na verdade, essa iniciativa do Laboratório de Teatro nasceu da experiência de uma criação com o Teatro Paris-Villette, em 1999, na qual os artistas convidados eram incentivados a irem ao encontro dos mais diversos públicos. $E$, a partir do nosso espetáculo "Alice Droz", de Miguel Angel Sevilla, decidimos trabalhar mais especificamente com os jovens da vizinhança, do EREA ${ }^{43}$ Jean-Jaurès, localizado no 19o bairro ${ }^{44}$ de Paris, na seguinte sequência: a peça era reescrita de maneira livre pelos próprios jovens e pelo autor, de acordo com suas vontades, e, logo em seguida, eu passava a proposta para a forma teatral. Assim, nosso trabalho inicial teria um sentido suplementar, visto que esses jovens se reapropriavam dele, com muito entusiasmo e zelo. $\mathrm{Na}$ continuidade dessa criação, foi projetada uma jornada teatral em outros bairros parisienses. Inclusive, o diretor do teatro L'Entrepôtnos pediu para "entrar em contato com todos os atores socioculturais do 14 o bairro. Convencidos pela nossa última experiência, entramos em contato com o EREA Croce Spinelli, onde o Laboratório de Teatro esteve presente por cerca de uma década. Essa ação obteve reconhecimento institucional global e foi parabenizada tanto pela prefeitura quanto pela instituição escolar.

Em 2003/2004, os rapazes puderam integrar o EREA Croce Spinelli, até então exclusivo às jovens. No verão de 2005, o Laboratório de Teatro participou do Festival de Avignon, graças ao financiamento obtido do Fundo Social Europeu (FSE). Esse evento proporcionou uma experiência extremamente rica para todos os jovens. Em 2010, devido à parceria com o EREA, fomos solicitados pela equipe de desenvolvimento local do $14^{\circ}$, da Prefeitura de Paris, para trabalharmos no desenvolvimento educacional. Isso nos permitiu encontrar uma nova parceria, dessa vez com o Centro Sociocultural Maurice Noguès, Porta de Vanves, que acolheu o Laboratório de Teatro, local onde trabalhamos até hoje.

D.M.: Como foi essa aproximação entre vocês e os jovens adolescentes? E como foi o trabalho de vocês para se relacionar com eles?

\footnotetext{
43 N.A.: Estabelecimentos Regionais de Ensino Adaptado, sob a tutela da Educação Nacional. São estabelecimentos públicos locais, cuja missão consiste em se encarregar de adolescentes em grande dificuldade escolar e social ou com alguma deficiência.

${ }^{44}$ N.T.: A cidade de Paris é dividida administrativamente em 20 arrondissements; optou-se pela tradução desse termo como 'bairros'.
} 


\section{RevistAleph}

N.S.: No EREA Croce Spinelli, o protocolo de trabalho era direcionado às turmas do $9^{\circ}$ ano, partindo de um projeto com toda a turma, até um voluntariado de maneira transversal, com o acompanhamento dos professores. Desenvolvemos essa atividade com grandes exigências, partindo de As Suplicantes ${ }^{45}$ de Ésquilo, texto marcado pela questão do matrimônio forçado. No primeiro momento, nossa proposta foi recebida com grande rejeição pelas meninas mais jovens, que assumiram uma postura bastante defensiva, mas, com o tempo, as resistências foram cedendo, dando lugar a um forte engajamento, o que favoreceu o surgimento de apaixonantes improvisações. No mesmo contexto, foram propostos outros autores ao grupo (Molière, Brecht, Shakespeare...), cujos textos tocaram profundamente esses jovens.

E, então, em 2007, durante uma nova criação de Khadija vient à Paris ${ }^{46}$, surgiu um protocolo de trabalho inédito em forma de questionário. O enredo proposto ao grupo, já misto, foi o seguinte: uma criança vem da África a Paris. Imediatamente o grupo optou por uma personagem feminina. Alguém espera por ela? Por que ela saiu de lá? O que se passa com ela? Ela está sozinha nessa empreitada? A improvisação durou dois meses, durante os quais Miguel Angel Sevilla concluiu o texto.

D.M.: Como assisti à apresentação desse trabalho, pude ver que o objeto criado é, de fato, extraordinário e, ao mesmo tempo, contemporâneo e poético, se situando no "entremeio" do imaginário e do real. Khadija deixa Abidjan por Paris em busca de Kélélé, o menino que salvou sua vida. No decorrer dessa longa e arriscada jornada em direção a uma cidade distante e desconhecida, uma cegonha e um papagaio a acompanham e tomam conta dela. Ao longo desse caminho, ela se depara com diversos personagens que participarão dessa aventura. Essa peregrinação metafórica mostra, nas entrelinhas, o percurso de exílio dos migrantes, obrigados a abandonar suas famílias, suas regiões, línguas, cheiros, sons, as cores da terra que os viu nascer e à qual eles se apegaram. A acolhida da metrópole pode ser considerada, no mínimo, retraída e distante. As formalidades administrativas e uma certa indiferença a sua chegada, tendendo quase à inospitalidade, são felizmente compensadas no coração do subúrbio, graças ao $\begin{array}{llll}\text { entusiasmo caloroso de alguns. } & \text { de }\end{array}$

\footnotetext{
$\overline{45}$ N.A.: As cinquenta filhas de Dânao - as danaídes- expressam sua aversão ao casamento, ao qual os cinquenta primos delas, filhos de Egito, pretendem forçá-las a ter com os mesmos (466-463 a.C.).

${ }^{46}$ N.T.: Khadija vem a Paris.
} 


\section{RevistAleph}

N.S.: É exatamente disso que se trata. Vemos claramente como essa história vai sendo alimentada pelas representações desses jovens, eles mesmos atravessados pela questão do exílio... Aliás, é significativo poder constatar que, dez anos depois, já em 2017, um outro grupo no Laboratório de Teatro, constituído por crianças muito mais jovens, do ensino básico, apropriou-se da peça com muito interesse e entusiasmo.

Em 2010, iniciou-se uma nova dinâmica: a ideia era encenar em dois hospitais parisienses, o hospital Necker Enfants Malades e a Maison de Solenn. Esse exercício extremamente difícil de encenar para crianças hospitalizadas, em sofrimento e com grande expectativa, atribuiu, aos jovens, uma nova responsabilidade, dando um pouco mais de sentido a essa intimidade compartilhada com os textos, que podia, para alguns, parecer de difícil acesso.

Nossa premissa inicial, para abordar jovens feridos com trajetórias de vida, muitas vezes caóticas, foi escrever para eles e com eles, sem nos concentrarmos apenas em uma escrita improvisada no palco, oferecendo-Ihes cultura.

D.M.: Seria o modelo de cultura ${ }^{47}$ como ferramenta civilizatória, construído a partir da renúncia pulsional, como Freud propôs?

N.S.: Sim, podemos entender dessa forma. Esses jovens estão em busca de apoio e consideração. Eles se aproximaram bastante de Miguel Angel [Sevilla], que é uma figura de autoridade, paternal e protetora, de certo modo um "gênio", sempre presente nas sessões de improvisação, mas que quase nunca intervém. Ele acolhe o que esses rapazes e moças têm a oferecer, para, no final, dar corpo a um texto, abrindo-lhes novas portas.

A sessão de improvisação é um momento lúdico que requer, contudo, um envolvimento cada vez maior na expressão ou no controle de emoções. As linhas trabalhadas são diversas: corpo e espaço, emoção, descoberta e desafio de relações, voz, concentração, imaginação...

D.M.: Miguel Angel Sevilla se aproveita de fragmentos de efeito que surgem na fala dos jovens e das frases "soltas no ar", para construir uma narrativa que exija imaginação da parte deles?

\footnotetext{
${ }^{47}$ N.A: "A palavra 'cultura' designa a soma total das realizações e dispositivos pelos quais nossa vida afastase daquela de nossos ancestrais animais e que servem a dois fins: a proteção do homem contra a natureza e a regulação das relações dos homens entre si." (FREUD, 1929)
} 


\section{RevistAleph}

N.S.: Ele absorve intrinsecamente esses movimentos que, unidos, tecem uma matéria particularmente rica, diversificada e viva. As temáticas escolhidas sempre se unem, ainda que por vias tortuosas, às problemáticas suscetíveis de reverberar nas próprias preocupações dos jovens. O jogo teatral permite que se sintam na pele de um personagem, em uma espécie de casulo, protegendo-os e possibilitando que expressem sentimentos reprimidos. O que pode surpreendê-los algumas vezes.

D.M.: Ou seja, viver sem "arriscar sua própria pele", que é, aliás, o desafio fundamental da adolescência e, ao mesmo tempo, passagem e crise: renunciar aos objetos infantis, a fim de construir essa nova identidade, sem se perder. Essa imensa mobilização de recursos internos participa de um movimento de criação completo, que solicita tanto o corpo quanto a psique. E, assim, observamos como o meio teatral e corpóreo, ao oferecer ao adolescente um alter ego, constitui uma alternativa tranquilizante que acaba por consolidar esse processo de desenvolvimento, ocasionando o surgimento do sujeito.

N.S.: Quanto a mim, posso dizer que o teatro me salvou. Por ter sido uma adolescente tímida e sempre sob pressão, encontrava dificuldades em me comunicar e me relacionar com os colegas. Foi o teatro que modificou, radicalmente, minha relação com os corpos, tanto com o meu quanto com o dos outros. Foi para mim uma espécie de redescoberta e abertura ao mundo; sempre tive certeza da relevância do teatro e da metamorfose que ele oferece. Acredito gostar da adolescência, exatamente por essa construção que ela representa estruturalmente, essa agitação, essa urgência de desejos conturbados, que são controlados pela própria expressão teatral, em um sábio e enigmático diálogo entre palavras e corpos.

D.M.: E essa experiência teve outros benefícios?

N.S.: A experiência do prazer. Um intenso prazer em encenar, dizer, fazer parecer, revelar, sugerir e me expressar. E em sonhar também, de onde vem o nome da nossa companhia! O meio teatral é um "condutor", um fio tênue e frágil que liga nós mesmos aos outros. Tranquilizar, exaltar, divertir. Tranquilizar o jovem quanto a sua legitimidade, modificar a visão de si mesmo, gerar em si uma energia positiva. Arriscar-se, também, no contato com o outro, em um mundo onde a crueldade das relações humanas pode ser atenuada com sensibilidade. Ou, ainda, se dar conta, exatamente por se tratar de uma ficção, da violência arcaica que é parte intrínseca da vida. 


\section{RevistAleph}

D.M.: Parece que essa violência exposta favorece, pelo viés dos movimentos de identificação projetiva, o reaparecimento de desejos, angústias e fantasmas da infância (incorporação, devoração, fragmentação), que são encontrados, também, de forma privilegiada, nos contos de fadas ${ }^{48}$ : o furor, a crueldade sem freio e sem limites que caracteriza certos personagens, a rivalidade destrutiva, o incesto, o infanticídio... Essa prática - se considerada, stricto sensu, como o teatro de pulsões hostis ultrapassando cada vez mais os limites - seria ideal para provocar a catarse? Pensamos, aí, no "teatro da crueldade $^{49 "}$, de Antonin Artaud, que tinha a função de propor ao espectador um material onírico, capaz de exaltar pulsões e provocar nele uma sublimação: "O teatro [...] serve-se de todas as linguagens: gestos, sons, falas, fogo e gritos surgem exatamente no momento em que o espírito precisa de linguagem para se manifestar" (ARTAUD, 1938). No seu ponto de vista, o Laboratório de Teatro seria um espaço terapêutico?

N.S.: A área da saúde não é de minha competência. Não sou artista-terapeuta. Posso, até, me perguntar se o que produzo é, stricto sensu, uma mediação. A questão da arte como terapia reaparece em cada uma das formações que realizo no meio psiquiátrico. Se há um benefício terapêutico, certamente não é por acaso. Trata-se de uma consequência do projeto artístico proposto. E não posso deixar de notar que essa proposta do Laboratório de Teatro tem um forte investimento da parte dos adolescentes e jovens adultos, que uma bela dinâmica é criada e que há necessariamente um impacto no plano individual. Observamos, além disso, uma evolução na maioria desses jovens, no sentido de uma maior abertura ao mundo, maior autonomia, capacidade de ousar falar. Eles e elas têm coisas a dizer, muitas vezes difíceis de formular através dos códigos preestabelecidos. Imaginar-se na pele de outro ou outra, em um determinado espaçotempo, em um contexto intacto e apropriado, permite expurgar o indizível e, então, sem dúvida alguma, se sentir existir de outra forma.

D.M.: “O teatro sonhado por Artaud [...] renova o sentido da vida" (KLEIN, 2015). Você acha que a forma de teatro que se propõe no âmbito do Laboratório de Teatro tem, para esses jovens, algum efeito sobre a forma de se colocarem no mundo?

\footnotetext{
$\overline{48}$ N.A.: Cf. Irmãos Grimm, o Conto do Zimbro, 1812: "Minha mãe me matou. Meu pai me comeu. Minha irmã enterrou meus ossos debaixo do zimbro."

${ }^{49}$ N.A.: O termo 'crueldade', aqui, remete ao apetite pela vida.
} 


\section{RevistAleph}

N.S.: Você propôs uma frase de René Char para chamar a atenção dessa troca. Ela me ajuda a responder à sua pergunta sobre o teatro sonhado por Artaud, como um meio de renovar o sentido da vida. Não sei se a forma de teatro que pratico com os jovens do Laboratório é o que realmente será capaz de renovar o sentido de suas vidas. Porém, a questão de se arriscar, muito presente no ato de representar e pensar uma representação, pode ajudá-los a renovar a relação com o mundo. $O$ ato de representar os torna abertos ao mundo e aos outros. O mundo torna-se mais vasto, mais rico de possibilidades, e o risco surge como uma chance ou um obstáculo a superar. Além disso, a jornada do personagem da peça para alcançar seu objetivo coloca o jovem, de imediato, diante de uma noção de tempo enriquecida, renovada, semelhante a um caminho a percorrer. No palco, um ator, como o personagem que representa, mesmo que esteja imóvel, age. Essa experiência pode ser construtiva. Por definição, tornar-se sujeito de sua vida é ser ativo, de uma forma ou de outra. E encontrar ou procurar um caminho é procurar ou encontrar uma abertura; então, em um sentido ou em outro, é renovar o sentido da vida. É por essa razão que, além do projeto artístico, propomos aos jovens um acompanhamento que os ajuda a se apropriarem das transformações ocorridas no Laboratório, para seus projetos profissionais, escolares e até mesmo artísticos, em parceria com profissionais competentes de diferentes campos socioeducativos. Sabemos, por experiência própria, que eles saem de lá encaminhados.

D.M.: Esse ambiente coletivo permite que os adolescentes encarnem as emoções que Ihes atravessam e que interajam uns com os outros. Portanto, permite que, eles mesmos, se descubram e ousem flertar com a alteridade, frequentemente vista como ameaçadora, devido à frágil essência narcísica dos jovens. Como você lida com esse risco?

N.S.: Através da ficção. O teatro é o lugar da ficção, em que todos esses elementos que compõem o teatro se desenvolvem; o oposto do real - O vazio ${ }^{50}$, como diz Peter Brook. Para mim, só faz sentido existir, na medida em que se possibilita a manifestação da ficção. Esse espaço, onde tudo pode vir a ser catártico, tanto para o público quanto para o ator, permite todos os choques, todas as confrontações e, para usar um termo teatral, todas as urgências. Esse tempo comprimido, no qual, por vezes, existe algo que poderia ser o objeto ou a matéria emocional de uma vida inteira, é legitimado pela "situação".

\footnotetext{
${ }^{50}$ N.A.: Título da obra epônima de Peter Brook, O espaço vazio. Escritos sobre o teatro, Paris, Le Seuil, 1977.
} 


\section{RevistAleph}

Interpretar Fedra pode ser muito divertido, mas, também, construtivo e esclarecedor. A questão relacional presente nessas ficções teatrais permite reproduzir qualquer coisa, sem jamais perder de vista o aspecto lúdico necessário, a infância da arte. O olhar benevolente do diretor, responsável pelo espaço cênico, e o dos companheiros de palco, ligados uns aos outros no trabalho teatral, acompanham e encorajam o participante em seu "trajeto" em direção ao outro. O outro como personagem, o outro como parceiro e, até mesmo, como "eu sou o outro"51", em Rimbaud.

D.M.: Criar, dizia Jean Genet, é "dar figura ao sofrimento que move todo homem" e implica um retorno constante à infância. Como é que o corpo, a voz, a emoção e o pensamento permitem ao adolescente dar forma a sua produção, sempre singular, no âmbito de seu encontro com o outro?

N.S.: O instrumento do ator é ele mesmo. E esses adolescentes, com os quais trabalho, devem aprender a se conhecer para que seu "instrumento" soe corretamente. Afinamos e aprendemos a tocar violão através da técnica, como aprendemos a entender o corpo. Aceitamos sua voz, aprendemos a conhecer seu registro emocional e o desenvolvemos. Creio que o sofrimento de que Genet fala é a base inconsciente desse trabalho psicoemocional. Os membros do Laboratório de Teatro aprendem, com prazer, a tornarem-se atletas psicoemocionais. O jogo de cena é o meio de acessar esse trabalho que é, de algum modo, um esporte, em que a singularidade de cada um é convidada a surgir com toda a liberdade. Uma parte de cada encontro do Laboratório de Teatro é dedicada a exercícios preliminares, preparando o ator para alcançar os resultados. Isso está a serviço de um projeto coletivo, que possui sentido e precisa de um esforço intelectual. Quando esses jovens entendem que são "condutores" e que, no palco, têm responsabilidade sobre o projeto, o autor, o público e os companheiros, e chegam, enfim, a se descentralizar de si mesmos, o sofrimento que move todo homem torna-se um meio, uma força para fazerem o que devem fazer: representar comédia ou tragédia, isto é, "mentir com verdade".

D.M.: A capacidade de reconhecimento interpessoal é um componente importante da adolescência, pois supõe um apelo ao outro. No entanto, esses adolescentes, "as

\footnotetext{
${ }^{51}$ N.A.: Carta de Rimbaud em 15 de maio de 1871 a Paul Demeny, na qual professa uma concepção original da criação artística, ao longo desta formação paradoxal: o poeta não domina tudo o que se exprime nele.
} 


\section{RevistAleph}

grandes vítimas do narcisismo52", foram incentivados ao fracasso, ao longo de experiências contrastantes, às vezes de extrema violência. Pode-se dizer que essa espécie de mediação corporal e teatral pode funcionar como uma revisão de valores, uma vez que apela para uma resposta do outro?

\section{O jogo de cena, o grupo, o palco...}

N.S.: Sim, pelo encontro com o público. Antes disso, pelo olhar do diretor, representante do público e, depois, pelo olhar curioso, solidário e exigente dos companheiros de palco. É a questão do olhar que aparece aqui. O primeiro olhar a ser direcionado é, aliás, o do comediante sobre seu personagem, que é sempre uma grande vítima da vida: Hamlet, As Suplicantes forçadas ao casamento e obrigadas a fugir, $O$ Avarento $^{53}$, Monsieur Badin ${ }^{54}$, A Megera Domada ${ }^{55}$... O segundo olhar é o do diretor sobre o ator/atriz: a direção do ator é uma maiêutica ${ }^{56}$. No espaço vazio, o olhar do diretor é o que faz com que o comediante dê a luz a tudo o que tem a oferecer imperceptivelmente. Estimular essa entrega que o jovem faz de si mesmo também é uma forma de estabelecer valores. Todo esse talento original é uma descoberta mútua. Um contrato tácito se instaura entre aquele que aceita deliberadamente se expor e aquele que Ihe indicará a direção ${ }^{57}$ e o conduzirá a uma revelação de si mesmo, para si mesmo.

D.M.: A adolescência é, primeiramente, a confrontação com a sexualidade, a perda, a incompletude, a renúncia aos objetos infantis; é o momento do encontro com o outro sexo. Esse espaço protegido visa mediar esse encontro? E, se sim, consegue?

N.S.: Para falar de algo pessoal, na adolescência, passei de um período místico, em que as cerimônias religiosas extasiavam-me, à descoberta do teatro. A questão da sexualidade, sem dúvida alguma, teve relação com o meu entusiasmo transbordante por essa expressão artística. Passei do religioso ao laico sem nenhuma dificuldade. Atualmente constato, na minha prática de diretora e professora, que essa questão da

\footnotetext{
${ }^{52}$ N.A.: Citação de Tony Lainé (1930-1992), psiquiatra e psicanalista.

53 N.T.: Comédia de Molière. (1668)

${ }^{54}$ N.A.: Monsieur Badin. Peça da vida de escritório. Peça em um ato de Georges Courteline, 1897.

${ }^{55}$ N.A.: Uma das três primeiras comédias de Shakespeare, em cinco atos, 1594.

${ }^{56}$ N.T.: Método socrático que consiste na multiplicação de perguntas, induzindo o interlocutor na descoberta de suas próprias verdades e na conceituação geral de um objeto. (Houaiss)

${ }^{57}$ N.A.: Etimologia latina, directio, onis: linha direta. Ou seja, impulsionar um movimento em um determinado sentido.
} 


\section{RevistAleph}

sexualidade é uma das mais comuns entre os adolescentes: experimentar a relação amorosa, o desejo, a esquiva e a sedução, a frustração e a falta são coisas que fazem parte do encanto do teatro. Se não é terapêutico, é, em todo caso, construtivo para o adolescente se descobrir nessa nova dinâmica, através de personagens fictícios. A aceitação da fragilidade ou do feminino, na prática amorosa para um menino ou, o inverso, na aceitação da força e da iniciativa para uma menina, são descobertas que o teatro permite e legitima. Não saberia dizer se diz respeito a uma mediação ou concretização simbólica, graças (homenageando Marivaux) Ao jogo do amor e do acaso... que interpretei, aliás, aos 15 anos, quando ingressei no Conservatório. Minha prática docente e o Laboratório de Teatro, em todo caso, confirmam que não sou uma exceção!

D.M.: Sua resposta suscita algumas reflexões. A primeira diz respeito à tensão entre sagrado e profano. Será que essa transição do religioso ao laico mostrou-se realmente tão fluída, na transposição de uma cena para outra, nos rituais e cerimônias em relação aos dois lados do "código"-, mecanismos de organização simbólica, muito presentes, tanto na cerimônia religiosa quanto no teatro; ou seja, na dimensão estruturante deles? E, além disso, a exaltação é parte intrínseca da adolescência, diante do forte idealismo que a atravessa e da necessidade de acreditar que é realmente estruturada. Julia Kristeva fala, até mesmo, de "síndrome de idealismo ${ }^{58 " . ~ E n f i m, ~ a ~}$ capacidade desses jovens, meninos e meninas, de procurar, no mais íntimo de si, traços estabelecidos para o outro sexo, certamente remete à noção da bissexualidade psíquica. Pois, se as modificações do corpo determinam que o adolescente se insira em um corpo "sexualizado", permitindo que se situem no meio de um sistema de trocas simbólicas, todo ser humano é portador, pelo viés das identificações paterna (com homens) e materna (com mulheres), de uma parte masculina e feminina, as quais encontram, sem dúvida, no jogo de cena e no palco, um espaço de expressão privilegiado - fazendo referência ao "mentir com verdade" que você tanto evocou...

N.S.: Voltando à questão do ritual estruturante, poderíamos dizer que entrar em cena e sair de cena é como nascer de novo e aprender a morrer. Para os jovens do Laboratório, a forte emoção e o excesso de vida contidos na representação são equivalentes ao enorme cansaço e à saudade sentida no fim de um projeto. Essa

\footnotetext{
${ }^{58}$ N.A.: Julia Kristeva, conferência dada à Sociedade Psicanalítica de Paris, em 8 de fevereiro de 2010.
} 


\section{RevistAleph}

experiência é muito forte. Eles sempre enviam mensagens, telefonam e levam um certo tempo para fazer a passagem entre esses dois eventos: representação e ausência de representação. $E$, frequentemente, é o início de um outro projeto que lhes permite superar o luto do anterior, se desapegar dele.

D.M.: Que linda metáfora! Essa problemática da separação está bem no âmago da adolescência. Aceitar a renúncia aos objetos de apego infantil, à imagem do filho ideal, aceitar se arriscar a se tornar outro(a) ou, ainda, enfrentar o desafio de deixar a infância... Talvez pudéssemos citar as palavras de Rilke: “Ah, quanto vivi o sentido da palavra 'partida'. Vejo-o tão obscuro, insuperável e cruel, tendendo a vir em nossa direção pela última vez, como um vínculo harmonioso que logo se desfaz ${ }^{59}$." Diante da amplitude da tarefa desses jovens em desenvolvimento, como exatamente a cena teatral e corporal pode favorecer a sublimação de uma instintividade transbordante? $E$, considerando que o simbólico se desdobra na fala,que modalidades específicas articulam-se com a atuação do corpo?

N.S.: Uma palavra me vem à mente: equilíbrio, equilíbrio entre emoção, pensamento e corpo, para alcançar a fala. Stanislavski cita dois tipos de atores: o ator nato e o secundário. $\mathrm{O}$ ator nato seria aquele cuja expressão pulsante, bruta e instintiva encontra-se nele; já o ator secundário é aquele que carrega seu corpo como o caracol carrega sua casa, mesmo contra a vontade. $\mathrm{O}$ ato de criação teatral é apenas o equilíbrio entre essas duas tendências. Do meu ponto de vista, essa procura de equilíbrio é a modalidade através da qual a fala articula-se com a atuação do corpo.

Sinto, imediatamente, quando a fala do jovem em cena está na ponta da língua; se ele está ausente de si em relação ao corpo, ao pensamento e à emoção. Andrée Tainsy ${ }^{60}$ menciona "uma fala sem sombra projetada". O meu trabalho é ajudar os jovens a encontrar a harmonia e a sombra projetada, ou seja, o pensamento e/ou a emoção que habitam neles e Ihes dá corpo. E quando ele ou ela encontram isso, sem dúvida a sublimação acontece. Inclusive, lembro-me de uma jovem que tinha regularmente surtos de violência no grupo. Seu melhor trabalho, refletindo sobre a personagem, foi dar corpo e voz a uma jovem prostituta, revoltada na prisão. Seu longo processo intelectual e artístico foi, para mim, um dos mais surpreendentes: vendo-a dar corpo à personagem,

\footnotetext{
${ }^{59}$ N.A.: Trecho do poema "Partida", de Rainer Maria Rilke (1997).

${ }^{60}$ N.A.: Atriz belga (1911-2004). Ela se tornou pensionista da Comédia Francesa em 1982.
} 


\section{RevistAleph}

através de uma fala que, a princípio, não era a sua, era como vê-la transcendendo e indo além dela mesma. Nessa jovem, por exemplo, a instintividade transbordante transformava-se, em instantes, em uma grande arte. Hoje, ela trabalha como mediadora em um lar para migrantes. Um dia, ela me confessou estar surpresa de ter descoberto essa capacidade de resolver conflitos; logo ela que passava o seu tempo provocando-os. Eu gostaria de abordar a questão do projeto através deste exemplo. Nos cursos que ministro, perguntam-me, com frequência, como escolhemos um projeto teatral; se há textos ou temas que não podem ser abordados em função de alguns problemas dos jovens?

Para mim, tudo pode ser matéria para criação. Respondo, então, que, depois de ter perguntado ao grupo de jovens sobre os temas que os preocupam, privilégio os que falam da nossa época, se inscrevem em suas realidades e me parecem interessantes para trabalhar. A partir disso, desse desejo compartilhado, acredito que tudo pode ser possível. Nosso próximo projeto será uma criação teatral a respeito da distopia ${ }^{61}$, como meio de refletir sobre um mundo sem diversidade, sem liberdade de expressão e sem igualdade entre homens e mulheres. Para a maioria dos jovens, a distopia é uma referência cultural forte, certamente em razão das inquietudes que ela transmite e das quais é expressão. Espero levar o grupo do Laboratório para além das trevas ligadas a esse gênero, a fim de refletirmos, sobre as aberturas possíveis, ou seja, os impasses constitutivos das distopias. Acredito que o projeto não deva ser escolhido em função de um eventual valor terapêutico, mas, sim, em função da possível relação teatral com a realidade, isto é, o que nos interessa e parece nos dizer algo.

D.M.: Como você lida com esse contexto de espaço e criação, que é suscetível a exageros impulsivos? Às vezes, você é pega de surpresa por algo que surge do nada, por aquilo que emerge em filigranas? Quais são seus recursos?

N.S.: Pela minha função, sou responsável por isso, seja como diretora, seja como responsável artística, isto é, responsável pelo projeto! Se, às vezes, sou pega de surpresa pelo jogo, não sendo terapeuta nem terapeuta artística, reajo como diretor ou como

\footnotetext{
${ }^{61}$ N.A.: Do prefixo grego dys (que indica uma anomalia) e topos (o lugar), narrativa ficcional representando uma sociedade imaginária governada pelo poder totalitário ou por uma ideologia prejudicial, de modo que ela impeça seus membros de alcançar a felicidade. Ela pode conduzir a uma contra-utopia. Por exemplo: A. Huxley, O admirável mundo novo (1932), K. Boye, Kallocaine (1940), G.Orwell, 1984 (1949), R. Bradbury, Fahrenheit 451 (1953), A. Burgess, Laranja mecânica (1962).
} 


\section{RevistAleph}

diretora de elenco: aquilo que o jovem propõe tem uma relação com a construção do personagem, sua atuação serve ao projeto, a relação traz alguma luz ou é uma outra história? Isso seria uma referência a Stanislavski. ${ }^{62}$ Eis os meus recursos e critérios. Claro que registro a informação que vai ajudar na minha relação com o comediante e na minha tarefa de fazer advir o que você nomeia de "sujeito", mas permaneço no meu lugar. Desse modo, eu peço ao jovem (que está em posição de ator) para retornar ao seu lugar de trabalhador a serviço do projeto artístico coletivo.

D.M.: Essa questão de "projeto artístico coletivo" é interessante, porque ela fala do "grupo". Ou todo grupo representa um personagem que contenha um "envelope" delimitador, protetor e une os indivíduos, ou o grupo constitui, de algum modo, um "envelope" sustentado pelo sujeito, ${ }^{63}$ favorecendo as disposições para a atuação, criatividade e simbolização, necessitando, no entanto, que as regras de funcionamento sejam enunciadas no início, para evitar riscos de fusão. Em relação ao Laboratório de Teatro, como esse seu pré-requisito posto e mantido é inseparável do trabalho realizado?

N.S.: Em minha opinião, não se pode ter um projeto artístico de grupo sem a seguinte premissa: respeito mútuo, respeito aos horários, respeito ao projeto e às funções de cada um, respeito ao espaço de cena - espaço frontal, bifrontal, em "U", em círculo ou no meio do público. Esta premissa, mínima, é o pré-requisito para que o grupo se sustente. No Laboratório de Teatro, constatamos que os jovens têm necessidade disso, e quando eles relaxam um pouco, o prazer desaparece, os problemas surgem (tentativa de domínio de um sobre o outro, a vontade de "estrelismo" pessoal, ausências e faltas repetidas). No que diz respeito à dimensão artística, está se manifesta de forma ainda melhor quando o contexto é adequado: constato sempre que, quando minhas instruções para uma improvisação não são claras, o resultado é triste. Quanto mais as minhas instruções são precisas, detalhadas e claras, mais a qualidade artística é observada, assim como o prazer do jovem ao adentrar a tarefa e concluí-la. O mesmo se aplica ao grupo: a

\footnotetext{
62 N.A.: Constantin Stanislavski (1863-1938), comediante, diretor e professor de arte dramática russa. Ele é um dos criadores do teatro de arte de Moscou e o autor de $A$ Formação do autor e de $A$ construção do personagem. Seu ensinamento, fundado sobre a memória afetiva e a própria experiência dos atores, influenciou especialmente o famoso curso nova-iorquino de teatro Estúdio dos Atores de Lee Strasberg e Elia Kazan.

63 N.A.: Didier Anzieu (1923-1999), O grupo e o inconsciente: o imaginário do grupo (1975), Paris, Dunod, 1999. Psicanalista, professor emérito de psicologia da Universidade de Paris X - Nanterre e membro da Associação Psicanalítica da França (APF).
} 


\section{RevistAleph}

situação deve ser colocada, precisa e nunca inflexível. Existe uma interação entre o grupo e as pessoas que trabalham nele, e isso permite fazer evoluir o contexto. Acrescento algo pessoal: renovo-me em meu trabalho diante dos jovens, graças a essas evoluções que são necessárias. A palavra francesa "repetição" ${ }^{64}$, que define o trabalho preparatório para as apresentações públicas de um espetáculo, é paradoxal. De fato, a repetição consiste em um desenvolvimento sucessivo e enquadrado de diferentes momentos a serviço da construção artística; mas não se trata, em nenhum dos casos, de uma repetição mortal como a anterior, mas de um processo evolutivo onde o jovem encontra, a cada vez, um novo alimento para o seu trabalho. Essas "repetições" ${ }^{65}$ no fundo não são e não oferecem um quadro que permite a liberdade criativa e nem desenvolvem a adaptabilidade dos jovens.

D.M.: Acredito que você gostaria de trazer esclarecimentos sobre a composição do Laboratório de Teatro. Você acolhe jovens cujas dificuldades podem ser muitas: carências sociais, escolares, afetivas, mas, também, jovens apresentando deficiência - autistas ou com problemas cognitivos. Se a arte teatral não cura, por definição, restabelecendo supostamente uma espécie de automatismo redutor, ela, sem dúvida, ajuda aqueles que sofrem de profundas feridas e desordens interiores a viver. Nesta lógica, o talento pela expressão teatral, que manifestam alguns desses jovens, não pode revelar excelentes atores profissionais? Aliás, como você consegue criar uma dinâmica harmoniosa, onde cada um encontra a oportunidade de se expressar?

N.S.: A ideia de misturar deficiente e não deficiente, amadores e profissionais, e adiciono ainda os jovens e velhos, é fruto do acaso. Anos atrás, eu apresentava um espetáculo do EREA, sem essa mistura, e uma pessoa da fundação da França me sugeriu acolher no seio do grupo alguns jovens da turma $\mathrm{Ulis}^{66}$, que tinham alguma necessidade especial. Resumindo, digamos que eu tenha acolhido essa ideia com curiosidade. Hoje, faz mais de dezessete anos que todos nós do Laboratório de Teatro constatamos os benefícios dessa mistura humana e artística. A diversidade e a singularidade das trajetórias adicionam e criam uma dinâmica artística única. A delicadeza da atuação de

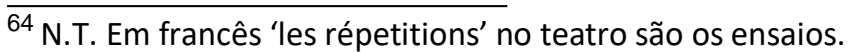

${ }^{65} \mathrm{~N}$. T.: Trata-se das repetições "mortais", inconscientes, já mencionadas.

${ }^{66}$ NT.: ULIS - Sigla de (L'Unité Localisée pour l'inclusion Scolaire - Unidade Localizada para Inclusão Escolar)é um dispositivo no seio de uma escola primária, secundária e tecnológica ou profissionalizante, cujo projeto tem por missão acolher de maneira diferenciada alunos em situações de necessidades especiais.
} 


\section{RevistAleph}

uma jovem com síndrome de Down, a fantasia de um jovem autista e a poesia corporal de um jovem deficiente físico são, em si mesmas, riquezas que transformam e expandem os olhares dos outros jovens, fazendo com que relativizem suas próprias dificuldades. Eles se vêem igualmente como "fonte", e isso os valoriza. A escolha dessa mistura tornou-se a característica do Laboratório de Teatro; nosso constante trabalho e objetivo é que cada um encontre seu lugar nessa organização. O equilíbrio é possível e o lugar dado a cada um é ainda melhor pela duração do trabalho que escolhemos: cada projeto de criação dura um ano e meio, cabendo a nós escolher diferentes destaques e encontros intermediários com o público. É nessa duração que o equilíbrio é obtido, assim como a qualidade artística do conjunto e os progressos de cada um. Essa duração de um ano e meio poderia causar medo, se fosse colocada imediatamente, mas ela se impõe, ela mesma, aos poucos e de acordo com o desejo dos jovens de querer cumpri-la. Por enquanto, Miguel Angel Sevilla encontra um meio de colocar cada um dentro da peça. A equipe supervisora considera as particularidades de uns e de outros, e o trabalho alterna o tempo de ensaio com todos juntos ou individualmente, mas sempre sob o olhar de todos e com sessões individuais comigo. Esses momentos individuais são muito intensos e muito importantes; eles me ajudam a não perder de vista a pessoa que poderia se sentir apagada no projeto.

D.M.: Para concluir, o palco não oferece aos adolescentes e jovens adultos, através dessa experiência única do teatro, a oportunidade de atualizar seus afetos em um contexto seguro, garantindo uma memória coletiva, conjugando mitos, rituais, dança, música e literatura?

N.S.: Sim, com certeza. É nesse conjunto, que chamamos de arte e cultura, que eles descobrem que a vida é uma bela aventura a percorrer, o que, sem dúvida, já sabiam. 


\section{RevistAleph}

\section{REFERÊNCIAS}

ANZIEU D., O grupo e o inconsciente: O imaginário do grupo, Ed. Dunod, Paris,1999.

ARTAUD A., O teatro e seu duplo, Ed.Gallimard, coll. « Folio », Paris, 1985.

BOYE K., kallocaine, Ed. Les Moutons Électriques, Bordeaux, 2016.

BRADBURY R, Fahrenheit 451, Ed. Gallimard, Paris, 2000.

BROOK P., O espaço vazio. Escritos sobre o teatro, Ed. Seuil, Paris, 1968.

BURGESS A., A laranja mecânica, Ed. Robert Laffont, Paris, 2010.

CHARTON H., Alain Knapp e a liberdade na improvisação teatral, Ed. Garnier, Paris, 2017.

FREUD S., O mal estar na cultura, Ed. PUF, Paris, 2010.

GARCIA-FONS T., Gassmann X., "Adolescência criativa », Carta da infância e da adolescência, Ed ERES, Paris, 2007

GRIMM J., GRIMM, W., Contos para as crianças e a casa, coll. «Fantástico », Ed. Corti, Paris, 2009.

HUXLEY A., O admirável mundo novo, Ed. Livre de Poche, Paris, 2001.

KLEIN JP, Teatro e dramaterapia, Ed. PUF, Paris, 2015.

KNAPP A., A.K, Uma escola de criação teatral, Ed. Actes Sud Papiers, caderno nº7 Arles, 1993.

ORWELL G., 1984. Ed. Gallimard, Paris, 1972.

RILKE RM., " Partida », em novos poemas I, Ed. Gallimard, coll. « Ed. Pléiade », Paris, 1997.

STANISLAVSK C., " $\boldsymbol{A}$ construção do personagem ", em Cadernos de nota sobre O jardim das cerejas e As três irmãs, Ed. Aux Forges de Volcan, Paris, 2011. 